\title{
Caracterização física e físico-química de frutos de Spondias dulcis Parkinson de diferentes microrregiões do Estado da Paraíba
}

\author{
José Roberto Chaves Neto ${ }^{1}$, Silvanda de Melo Silva ${ }^{2}$
}

Universidade Federal de Santa Maria-UFSM, Santa Maria, RS. ${ }^{2}$ Universidade Federal da Paraíba-UFPB, PB. E-mail: jose.chavesneto@gmail.com

\section{Resumo}

Os frutos da cajá-mangueira (Spondias dulcis Parkinson), apresentam alto potencial para o mercado de frutas frescas, e também características desejáveis para o processamento, devido às suas características sensoriais e nutricionais, apresentando também boas perspectivas de cultivo e comercialização, de modo a permitir o desenvolvimento da região. O objetivo do presente estudo foi caracterizar frutos de cajámangueira colhidos na maturidade comercial (coloração totalmente amarela) das microrregiões do Brejo Paraibano (BP), João Pessoa (JP) e Litoral Norte (LN), Estado da Paraíba, Brasil. Utilizou-se o delineamento inteiramente casualizado com três tratamentos (microrregião), com 15 frutos, sendo cada fruto uma repetição para caracterização física e três repetições de $250 \mathrm{~g}$ de polpa para a caracterização físico-química. A caracterização dos frutos foi realizada através de 11 avaliações de: comprimento (L), diâmetro (D), firmeza (F), peso do fruto (PF), rendimento de polpa (RP), porcentagem de casca (PC), porcentagem de semente (PS), pH, sólidos solúveis totais (SS), acidez titulável (AT) e relação SS/AT. As características físicas e físico-químicas dos frutos da microrregião da Costa Norte indicam que estas podem ser utilizadas tanto para o consumo de frutas frescas como para a industrialização. Os resultados da análise de variância mostraram a existência de correlações lineares simples significativas entre as características físicas e químicas analisadas, indicando a existência de caracteres como tamanho do fruto ou teor de sólidos solúveis para estimar parâmetros de produção, seleção e qualidade de frutos da cajá-mangueira.

Palavras-chave: cajá-mangueira; cajaraneira; amadurecimento; fruta exótica; pós colheita.

\section{Physical and physical-chemical characterization of fruits of Spondias dulcis Parkinson of different microregions of the State of Paraíba}

\begin{abstract}
The fruits of the cajá-mangueira (Spondias dulcis Parkinson), Present high potential for the market of fresh fruits, and also desirable characteristics for the processing, due to their sensorial and nutritional characteristics, being presented with good perspectives of cultivation and commercialization of in order to allow the development of the region. The objective of the present study was to characterize cajámangueira fruits harvested at commercial maturity (totally yellow color) from the microregions of the Brejo Paraibano (BP), João Pessoa (JP) and North Coast (LN), State of Paraíba, Brazil. A completely randomized design with two treatments (Microregion) was used, with 15 fruits, each fruit one repetition for physical characterization and three replicates of $150 \mathrm{~g}$ of pulp for the physical-chemical characterization. The characterization of the fruits was carried out through 11 evaluations of: length (L), diameter (D), firmness $(F)$, fruit weight (FW), yield of pulp (YP), percentage of bark (PB), percentage of core (PC), pH, total soluble solids (TSS), total titratable acidity (TTA) and SS/TTA (ratio). The physical and physicochemical characteristics of the fruit from the North Coast microregion indicate that these can be used both for the consumption of fresh fruits and for industrialization. The results of the analysis of variance showed the existence of significant simple linear correlations between the physical and chemical characteristics analyzed, indicating the existence of characters such as fruit size or soluble solids content to estimate production, selection and fruit quality parameters of the cajá-mangueira.
\end{abstract}

Keywords: Cajá-mangueira; golden apple; ripening; exotic fruit; postharvest. 


\section{Introdução}

A cajá-mangueira (Spondias dulcis Parkinson uu Spondias cytherea Sonn.) também conhecida como cajaraneira ou taperebá-dosertão, no Brasil, segundo Gomes (2007), já na América do Sul e Central é conhecida como 'mango jambo', 'jobo dela india ',' juplan '; Jamaica 'june plum' e em Cuba 'ciruela dulces', além de receber outras denominações como a de porco, golden apple orkedondong (DAULMERIE, 1994).

Esta espécie é uma frutífera arbórea tropical pertencente ao gênero Spondias e à família Anacardiaceae. Exótica no Brasil, tem sua origem na llha do Pacífico na região da IndoMalásia ao Taiti, é encontrada em toda a Ásia, Austrália, América Central e do Sul, Caribe e partes da África (BARTOO; BADRIE, 2005; LIRA JÚNIOR, 2005). No Brasil está frutífera ocorre forma esparsa em quase todo território, encontradas nas regiões semiáridas, sub-úmida e semi-úmida do nordeste brasileiro (LORENZI et al., 2006; JANICK; PAULL, 2008).

$O$ fruto da cajá-mangueira ( $S$. dulcis Parkinson) é classificado como drupa elipsoides, de cor amarelo intenso ao amadurecer, casca fina e lisa, polpa fibrosa e macia de sabor doce ou azedo semelhante ao abacaxi ou a manga. $O$ endocarpo chamado "caroço", é grande, branco, e dotado de fibras rígidas e espinescentes que mergulham parcialmente na polpa (LORENZI et al., 2006; MOURA et al., 2013). Este fruto é rico em fibras, sais minerais (magnésio, potássio, zinco, cobre, cálcio, fósforo e ferro) e algumas vitaminas ( $A, B 1, B 6$ e $C$ ), além de grande potencial para a agroindústria, podendo ser utilizado como matéria prima para produção de diferentes produtos (sucos, coquetéis, batidas, licores e sorvetes), no entanto, seu maior consumo está no mercado de frutas frescas (ISHAK et al., 2005; LORENZI et al., 2006; CARVALHO et al., 2008).

A qualidade dos frutos está relacionada aos seus caracteres físicos, que correspondem à aparência externa (tamanho, forma e cor da casca do fruto), associada a estes a composição química e nutricional dos frutos também são relevantes, devido a presença de vários constituintes físico-químicos e químicos na polpa. Que oferecem qualidade organoléptica e nutricional a estes frutos e aos produtos deles obtidos, desempenham um importante papel na alimentação humana. Estes atributos de qualidade são responsáveis pela sua aceitação definitiva no mercado, influenciando diretamente na aceitação dos alimentos (LIMA et al., 2002; CHITARRA; CHITARRA, 2005; PALIYATH et al., 2008; SANTOS et al., 2010).

Assim, o objetivo do presente trabalho foi caracterizar frutos de cajá-mangueira colhidos na maturidade comercial (coloração totalmente amarela) provenientes das Microrregiões do litoral norte, brejo paraibano e João Pessoa, Estado da Paraíba.

\section{Material e Métodos}

O experimento foi realizado no período de março a abril de 2013, no Laboratório de Biologia e Tecnologia Pós-Colheita do Centro de Ciências Agrárias da Universidade Federal da Paraíba (CCA/UFPB). Os frutos de cajá-mangueira (S. dulcis Parkinson) foram provenientes de plantas de cajá-mangueira de ocorrência espontânea em diferentes microrregiões do Estado da Paraíba: Microrregião do Brejo Paraibano (BP), Microrregião de João Pessoa (Microrregião de João Pessoa - JP) e Microrregião do Litoral Norte (LN). De acordo com a classificação de Köppen (1948) o clima da microrregião do BP é quente e úmido (tipo AS), com precipitação no outono e inverno, a microrregião JP apresenta clima tropical (tipo Am), com precipitação anual média de $1500 \mathrm{~mm}$ e a microrregião LN possui clima tropical (tipo Aw), com precipitação no verão.

Os frutos foram colhidos na maturidade comercial (coloração da casca totalmente amarela), antes da abscisão da planta (LIMA et al., 2002), manualmente nas primeiras horas do dia. Após a colheita, os frutos foram transportados em transportados em caixas térmicas ao Laboratório, onde foram previamente selecionados e separados quanto à ausência de danos físicos e em seguidas lavados em água corrente. Posteriormente os frutos foram sanitizados pela imersão em solução de hipoclorito de sódio $1 \%$ por 10 minutos.

Para a avaliações física foram utilizados 15 frutos para cada localidade, sendo cada fruto considerado uma repetição, estes foram avaliados quanto: comprimento (C) e diâmetro (D), estimados com a utilização de um paquímetro digital (Within $300 \mathrm{~mm}$ ), os resultados foram expressos em milímetros $(\mathrm{mm})$; 
peso do fruto determinado pela pesagem de cada fruto individualmente em balança semi-analítica (A42207c - Bel Engeneering), sendo os resultados expressos em gramas (g); firmeza da polpa dos frutos, realizada por meio de duas leituras por fruto utilizado um Penetrômetro de bancada digital (Magness/Taylor Pressure Tester), onde foi determinada a força de penetração necessária para que a ponteira com região de inserção de 2/16 polegadas de diâmetro penetre na polpa do fruto, e os resultados expressos em Newton (N) e rendimento de polpa, porcentagem de casca e semente, determinados pelo isolamento das partes e subsequente pesagem em balança semianalítica (A 42207c - Bel Engeneering), e os resultados expresso em porcentagem (\%).

Para as avaliações físico-químicas, os frutos foram processados em liquidificador para obtenção da polpa, estabelecendo 3 repetições 150 gramas de polpa, em seguida efetuou-se as seguintes determinações: potencial hidrogeniônico $(\mathrm{pH})$, medido com potenciômetro de bancada digital (Hanna, Singapura), com eletrodo de membrana de vidro calibrado com soluções de pH 4,0 e 7,0 (AOAC, 2016); teor de sólidos solúveis (SS), determinados por refratometria, com o auxílio de um refratômetro digital (Krüss-Optronic, Hamburgo, Alemanha), conforme normas analíticas do Instituto Adolfo Lutz (2005), resultados expresso em \%; acidez titulável (AT), determinada por titulometria com hidróxido de sódio $0,1 \mathrm{~N}$ utilizando-se fenolftaleína a $1 \%$ como indicador (BRASIL, 2008), resultados expressos em \% de ácido cítrico; relação sólidos solúveis/acidez titulável (SS/AT): obtida pela divisão simples dos valores de sólidos solúveis SS pelos de AT acidez titulável (BRASIL, 2008).

O experimento foi conduzido em delineamento inteiramente casualizado, os dados coletados foram submetidos ao teste de normalidade e homogeneidade dos erros, e posteriormente ao teste $\mathrm{F}$ da análise de variância (ANOVA). As médias foram comparadas pelo teste Tukey, adotando-se o nível de $5 \%$ de probabilidade de erro $(p \leq 0,05)$. Foi utilizado o programa estatístico Sisvar versão 5.6 (FERREIRA, 2014) para as análises.

$\mathrm{Na}$ análise multivariada fez-se uso da análise de correlação linear simples utilizando-se o software Statistica 7.0.

\section{Resultados e Discussão}

Os resultados obtidos para as características físicas encontram-se na Tabela 1. Verificou-se que o comprimento dos frutos provenientes das diferentes microrregiões apresentou resultados semelhantes, não diferiram significativamente entre si $(p \leq 0,05)$, cuja média foi de $65,64 \mathrm{~mm}$. Já para o diâmetro dos frutos de cajá-mangueira diferiram significativamente $(p \leq 0,05)$ entre as diferentes microrregiões. Os frutos provenientes da microrregião JP, destacaram-se por terem os maiores diâmetros, com média de $58,90 \mathrm{~mm}$ (Tabela 1).

Os valores de comprimento e diâmetro avaliados neste trabalho, foram próximos aos citados por Ishak et al. (2005), que descreveram comprimento de $66,80 \mathrm{~mm}$ e diâmetro de 50,20 $\mathrm{mm}$, mas superiores aos reportados por Silva et al. (2009), com 41,70 mm (comprimento) e 43,90 $\mathrm{mm}$ (diâmetro), para este fruto quando maduro. No entanto, inferiores aos citados por Damiani et al. (2011), com comprimento e diâmetro médio de 76,68 e $54,73 \mathrm{~mm}$, respectivamente. Segundo Viana et al. (2017), o comprimento e o diâmetro dos frutos in natura são características importantes para a agroindústria, visto que, por exemplo interferem no tempo de secagem quando estes frutos forem destinados ao processamento, e consequentemente no custo de produção devido à demanda energética.

De acordo com Carvalho et al. (2003), as condições edafoclimáticas, constituição genética, os tratos culturais, época de colheita, estádio de maturação e o tratamento pós-colheita, interferem nas características físicas e físicoquímicas dos frutos. Estas características são consideradas aspectos determinantes quanto a utilização e comercialização dos frutos e também sua utilização para elaboração de novos produtos (CHITARRA; CHITARRA, 2005; NASCIMENTO et al., 2014).

O peso dos frutos de cajá-mangueira avaliados neste trabalho, diferiu significativamente $(p \leq 0,05) \quad$ entre as microrregiões (Tabela 1), tendo as microrregiões do BP e de JP apresentado os maiores valores com médias de 99,82 e 97,47 g, respectivamente. Sendo bem superiores aos citados por Silva et al. (2009), que reportaram para frutos de cajámangueira maduros provenientes de Mossoró$\mathrm{RN}$, peso médio de $28,90 \mathrm{~g}$. Por outro lado, inferiores aos reportados por Damiani et al. (2011), que constataram peso médio de 136,0 g 
para frutos maduros desta mesma espécie, provenientes de Nova Veneza-GO.

O peso dos frutos de cajá-mangueira é maior do que o da ciriguela (Spondias purpurea L.), por exemplo, que pesa, em média, 10,16 g, colhidos na maturidade comercial (LIRA JÚNIOR et al., 2014). A massa fresca de frutos da umbucajazeira (Spondias sp.) oriundos do município de Areia localizado na Microrregião do Brejo Paraibano variou de 20,27 a 30,93 g (GONDIM et al., 2013), inferior aos dos frutos da cajámangueira, deste trabalho. A umbugueleira (Spondias sp.) pesou 10,63 g quando atingiu a maturação plena na planta, aos 147 dias após a antese (DANTAS et al. , 2016).

Determinar a firmeza dos frutos é fundamental para estabelecer técnicas e recipientes para o transporte e armazenamento, de modo a reduzir ao máximo os danos ocasionados pelos choques mecânicos, permitindo maior longevidade em prateleiras (FAGUNDES; YAMANISHI, 2001; JACOMINO et al., 2003).

A firmeza dos frutos de cajá-mangueira variou de 23,83 a $172,61 \mathrm{~N}$, sendo os frutos provenientes da microrregião do LN significativamente $(p \leq 0,05)$ mais firme, ainda permanecendo bastante firme apesar do avançado gradual de amadurecimento. A firmeza da polpa e do fruto pode ser influenciada pela cultivar, época de colheita, tratos culturais e condições ambientais, fator que foi comprovado neste trabalho (FAGUNDES; YAMANISHI, 2001).

O declínio da firmeza da polpa dos frutos está diretamente relacionado ao processo de amadurecimento, segundo Jacomino et al. (2003), durante este processo a firmeza pode diminui de 20 a 30 vezes, indicando que quanto mais avanço menor a firmeza. Esta característica física está correlacionada com o aumento das enzimas responsáveis pelas alterações estruturais na pectina, hemicelulose e celulose, que é a principal substância que forma as paredes primária e secundária das células vegetais (PAULL et al., 1999; CHITARRA; CHITARRA, 2005).

$O$ rendimento médio de polpa dos frutos de cajá-mangueira avaliados neste trabalho, foi igual a 73,97 \%, destacando-se os frutos das microrregiões do $L N$ e do $B P$, em virtude de apresentarem valores superiores, com 78,61 e $76,63 \%$, respectivamente os quais também foram iguais entre si e diferindo estatisticamente $(p \leq 0,05)$ dos frutos provenientes da microrregião de JP $(66,67 \%)$. Valores próximos ao desta pesquisa foram reportados por Silva et al. (2009) e Damiani et al. (2011) que descreveram rendimento de polpa médio de 73,58 e 61,02 \%, respectivamente, para este mesmo fruto no estádio de maturação maduro.

Tomando como base o valor mínimo de rendimento de polpa (40 \%) estipulado pelo Ministério da Agricultura, Pecuária e do Abastecimento (MAPA) Padrão de Identidade e Qualidade (PIQ) de frutos (BRASIL, 1999), o rendimento de polpa dos frutos do cajámangueira avaliado neste estudo independente da microrregião de procedência, apresentaram rendimento de polpa superior ao mínimo aceitável pelo PIQ do MAPA, característica satisfatória para industrialização.

Costa et al. (2015), também verificaram diferença quanto ao rendimento de polpa entre frutos de cajá (Spondias tuberosa, Arruda) provenientes de diferentes localidades do Estado da Paraíba. Estes mesmos autores relataram que a variação do rendimento de polpa dos frutos pode estar relacionada aos componentes de variação dos frutos dentro dos genótipos e também em função do município de procedência (microrregião).

Os valores de rendimento de polpa encontrados neste trabalho, são superiores aos de outras Spondias. Santos et al. (2010) e Gondim et al. (2013), reportaram para frutos de umbucajazeira (Spondias sp.), colhidos na maturidade comercial, rendimento de polpa variando de 69,70 a $68,53 \%$, os quais também foram superiores aos citados por Costa et al. (2015), que observaram para frutos de umbuzeiro ( $S$. tuberosa) colhidos maduros, rendimento médio de 65,08 \%. Em contrapartida, Menezes et al. (2017) reportaram valores semelhantes, com média de $74,30 \%$ de porcentagem em frutos de umbuzeiro (S. tuberosa) maduro.

Quanto a porcentagem de casca, os valores oscilaram entre 9,18 a $10,29 \%$, não diferindo significativamente $(p \leq 0,05)$ entre as microrregiões. Estes valores são inferiores aos citados por Gondim et al. (2013), que constataram porcentagem média de $22,08 \%$, em frutos de umbu-cajazeira (Spondias sp.), colhidos na maturidade comercial.

Para a porcentagem de caroço dos frutos de cajámangueira, observou-se média de $16,40 \%$, tendo os frutos provenientes das microrregiões do LN e do BP apresentado as menores porcentagem de caroço, com médias de 11,55 e 14,19 \%, respectivamente, sendo iguais entre si e diferindo 
$(p \leq 0,05)$ dos frutos provenientes da microrregião de JP, que apresentou maior média $(23,45 \%)$. A variação na porcentagem de caroço, em função da microrregião de procedência dos frutos, também foi constatado por Costa et al. (2015) em frutos de umbuzeiro ( $S$. tuberosa Arruda), do semiárido brasileiro. Valores de porcentagem de caroço próximos foram reportados por Carvalho et al. (2008) e Santos et al. (2010), que constaram médias de 31,81 e $20,31 \%$, respectivamente, em frutos maduros de umbu-cajazeira (Spondias sp.).
De acordo com Costa et al. (2015), a variância de determinada característica entre frutos de diferentes localidades, a exemplo do rendimento de polpa, é influenciada por componentes ambientais não controlados, pelo solo, pelo clima, pela idade das plantas e também pelas diferenças genéticas entre as plantas. A herdabilidade da variância permite a seleção de plantas mais produtivas apresentem frutos de melhor qualidade (GANGA et al., 2010).

Tabela 1. Valores médios de comprimento $(C-m m)$, diâmetro (D- $m m)$, peso do fruto (PF - g), firmeza (F-N), rendimento de polpa (RP - \%), porcentagem de casca (PC - \%) e porcentagem de sementes (PS - \%) de frutos de cajá-mangueira, colhidos maduros de diferentes microrregiões (Brejo Paraibano - BP; João Pessoa - JP; Litoral Norte - LN) do Estado da Paraíba.

\begin{tabular}{cccccc}
\hline \multirow{2}{*}{ Variáveis } & \multicolumn{3}{c}{ Microrregião } & \multirow{2}{*}{ Médias } & \multirow{2}{*}{ CV(\%) } \\
\cline { 2 - 4 } & $\mathrm{BP}$ & $\mathrm{JP}$ & $\mathrm{LN}$ & & \\
\hline C & $65,94 \pm 2,56 \mathrm{~A}$ & $70,37 \pm 3,20 \mathrm{~A}$ & $60,59 \pm 2,80 \mathrm{~A}$ & 65,64 & 17,22 \\
D & $50,68 \pm 3,21 \mathrm{~B}$ & $58,90 \pm 3,52 \mathrm{~A}$ & $44,37 \pm 2,65 \mathrm{~B}$ & 51,31 & 21,35 \\
PF & $99,82 \pm 9,06 \mathrm{~A}$ & $97,47 \pm 8,38 \mathrm{~A}$ & $64,64 \pm 8,75 \mathrm{~B}$ & 87,31 & 17,56 \\
F & $50,51 \pm 6,23 \mathrm{~B}$ & $23,83 \pm 6,59 \mathrm{~B}$ & $172,61 \pm 6,37 \mathrm{~A}$ & 82,32 & 32,27 \\
RP & $76,63 \pm 3,25 \mathrm{~A}$ & $66,67 \pm 4,70 \mathrm{~B}$ & $78,61 \pm 1,74 \mathrm{~A}$ & 73,97 & 11,83 \\
PC & $9,18 \pm 1,48 \mathrm{~A}$ & $10,29 \pm 3,95 \mathrm{~A}$ & $9,83 \pm 3,95 \mathrm{~A}$ & 9,77 & 25,68 \\
PS & $14,19 \pm 2,16 \mathrm{~B}$ & $23,45 \pm 3,87 \mathrm{~A}$ & $11,55 \pm 1,04 \mathrm{~B}$ & 16,40 & 26,27 \\
\hline
\end{tabular}

*Médias seguidas de mesma letra na linha não diferem pelo teste de Tukey ao nível de $5 \%$ de probabilidade.

A Tabela 2 demonstra os resultados obtidos quanto a caracterização físico-química. $\mathrm{O}$ $\mathrm{pH}$ diferiu $(\mathrm{p} \leq 0,05)$ entre frutos das diferentes microrregiões oscilando de 1,11 a 2,92, cuja média foi de 2,28 (Tabela 2). Damiani et al. (2011), reportaram valor próximo $(2,27)$ para estes frutos quando maduro oriundos de Nova Veneza, GO. Em contrapartida Silva et al. (2009), reportaram valores superior de $\mathrm{pH}$, com média de 3,47 para frutos de cajá-mangueira ( $S$. cytherea Sonn) no estádio de maturação maduro, provenientes de Mossoró, RN. De acordo com Benevides et al. (2008), para o processamento de frutos baixos valores de $\mathrm{pH}$ favorece a conservação dos produtos providente destes, visto que dificultar o desenvolvimento de microrganismos, por outro lado para o mercado de frutas frescas são apreciados valores de $\mathrm{pH}$ mais elevados, o que têm maior preferência por parte do consumidor (GONDIM et al., 2013).

O teor de sólidos solúveis (SS) dos frutos de cajá-mangueira das diferentes microrregiões avaliados, diferiram significativamente entre si $(p \leq 0,05)$ (Tabela 2), com média de $14,61 \%$. As maiores médias encontradas foram para os frutos das microrregiões BP e $\operatorname{LN}(15,40$ e $15,17 \%)$, respectivamente, sendo iguais entre si e diferindo significativamente dos frutos provenientes da microrregião de JP. Esses resultados foram superiores aos descritos por Aroucha et al. (2012), que constataram $11,77 \%$ de SS em frutos maduros de cajá-mangueira, e na faixa citada por Kohatsu et al. (2011), com 14,23 e 15,33\% para frutos armazenados por 6 dias a 4 e $25{ }^{\circ} \mathrm{C}$, respectivamente, enquanto Damiani et al. (2011), reportaram valores médios, superiores a 19,00\% de SS, em frutos de cajá-mangueira colhidos maduros.

Em relação à acidez titulável dos frutos de cajá-mangueira a média geral observada foi de $0,92 \%$ de ácido cítrico. A maior média encontrada foi para os frutos provenientes da microrregião do $L N$, com média de $1,14 \%$ de ácido cítrico, diferindo significativamente $(p \leq 0,05)$ das demais microrregiões (Tabela 2). Estes resultados são encontram-se próximos aos citados por Aroucha et al. (2012), 1,03 \% de ácido cítrico em frutos maduros colhidos, e na faixa citada por Silva et al. (2009), que reportaram valores variando de 0,79 a 1,44 \% de ácido cítrico, 
enquanto Lago-Vanzela et al. (2011), reportou valor médio, superior $(1,75 \%$ de ácido cítrico) para a acidez titulável, em frutos de cajámangueira.

Segundo Lima et al. (2002), frutos que apresentam acidez titulável superior a 1,00\% são apreciados pela indústria, visto que acidez elevada reduz a adição de ácido cítrico para padronização da polpa, além de inibir o desenvolvimento de microrganismos.

Para a relação sólidos solúveis/acidez titulável (SS/AT) dos frutos de cajá-mangueira, observou-se diferença significativa $(p \leq 0,05)$ entre as microrregiões, com valores variando entre 13,36 a 21,68 com média de 16,70, cujo maior valor foi obtido para os frutos provenientes da microrregião de JP (Tabela 2). Resultados semelhantes também foram constatados por Silva et al. (2009), que constataram relação SS/AT de 15,14 em frutos da mesma espécie estuda neste trabalho, colhidos maduros no município de Mossoró-RN.

De acordo com Dantas Júnior (2008) a variação da relação sólidos solúveis/acidez titulável entre frutos da mesma espécie, tem correlação direta com seus componentes acidez titulável e sólidos solúveis, porém, são influenciados por fatores ambientais e genéticos, o que justifica a variação significativa nos valores encontrados neste trabalho em função da microrregião de procedência.

De acordo com Silva et al. (2012), a relação SS/AT é uma das formas mais adequadas para avaliar o sabor, visto que é mais representativa que a medição isolada de açúcares e de acidez. Esta relação também pode ser utilizada como indicativo do estádio de maturidade fisiológica de frutos de várias espécies (CHITARRA; CHITARRA, 2005).

Os valores médios de SS, $\mathrm{pH}$ e AT encontrados neste trabalho para os frutos de cajá-mangueira das diferentes microrregiões, foram superiores aos valores mínimos (SS 9,0\%, $\mathrm{pH} 2,2$ e AT de $0,9 \mathrm{~g}$ de ácido cítrico $100 \mathrm{~g}^{-1}$ ) estabelecidos pelo Padrão de Identidade e Qualidade (PIQ) do Ministério da Agricultura Pecuária e do Abastecimento (MAPA) (BRASIL, 1999), para a polpa de frutos de cajazeira ( $S$. mombin), espécie frutífera do mesmo gênero da estudada neste trabalho.

Tabela 2. Valores médios de potencial hidrogeniônico $(\mathrm{pH})$, sólidos solúveis (SS), acidez titulável (AT - \% de ácido cítrico), relação sólidos solúveis/acidez titulável (SS/AT) de frutos de cajá-mangueira, colhidos maduros de diferentes microrregiões (Brejo Paraibano - BP, João Pessoa - JP, Litoral Norte - LN) do Estado da Paraíba.

\begin{tabular}{|c|c|c|c|c|c|}
\hline \multirow{2}{*}{ Variáveis } & \multicolumn{3}{|c|}{ Microrregião } & \multirow{2}{*}{ Médias } & \multirow{2}{*}{ CV (\%) } \\
\hline & $\mathrm{BP}$ & $\mathrm{JP}$ & LN & & \\
\hline $\mathrm{pH}$ & $1,11 \pm 0,04 C$ & $2,92 \pm 0,01 \mathrm{~A}$ & $2,81 \pm 0,05 B$ & 2,28 & 1,53 \\
\hline SS & $15,40 \pm 0,36 \mathrm{~A}$ & $13,25 \pm 0,25 B$ & $15,17 \pm 0,29 A$ & 14,61 & 2,08 \\
\hline AT & $1,02 \pm 0,01 B$ & $0,61 \pm 0,02 \mathrm{C}$ & $1,14 \pm 0,02 \mathrm{~A}$ & 0,92 & 1,77 \\
\hline SS/TA & $15,06 \pm 0,43 B$ & $21,68 \pm 0,66 A$ & $13,36 \pm 0,44 C$ & 16,70 & 3,12 \\
\hline
\end{tabular}

* Médias seguidas de mesma letra na linha não diferem pelo teste de Tukey ao nível de $5 \%$ de probabilidade. 
Observou-se, na Tabela 3, as correlações entre as características físicas e físico-químicas dos frutos de cajá-mangueira provenientes das diferentes microrregiões do Estado da Paraíba, Brasil. De acordo com Nascimento et al. (2014), correlações positivas entre duas características, apontam que estas são beneficiadas ou prejudicadas pelas mesmas causas de variação.

Guerra e Liveira (1999), descreveram uma classificação de intensidade de correlação, onde correlação para $p \leq 0,05$ é considerada muito forte $(r \pm 0,91$ a $\pm 1,00)$, forte $(r \pm 0,71$ a $\pm 0,90)$, média $(r \pm 0,51$ a $\pm 0,70)$ e fraca $(r \pm 0,31 a \pm 0,50)$. Desse modo, houve correlação positiva de intensidade muito forte $(0,992 *)$ entre as características comprimento e diâmetro dos frutos de cajámangueira, indicando que à medida que aumenta o comprimento dos frutos aumenta também o diâmetro (Tabela 3).

Esta correlação também foi citada por Costa et al. (2015), em frutos de umbuzeiro (S. tuberosa Arruda) provenientes de diferentes municípios do Estado da Paraíba, Brasil. Estes mesmos autores teorizam que a relação entre o comprimento e o diâmetro, permite estabelecer o formato dos frutos, sendo este formato uma característica atrativa principalmente para o mercado de frutas frescas, no entanto, também é apreciada pela indústria de processamento (FORTALEZA et al., 2005).

Observou-se correlação positiva significativa, em nível de $5 \%$, entre o peso do fruto, com o comprimento $\left(0,863^{*}\right)$, o diâmetro $\left(0,790^{*}\right)$ e o rendimento de polpa $\left(0,880^{*}\right)$ (Tabela 3). Tais resultados indicam que o peso do fruto foi diretamente proporcional ao comprimento e diâmetro, que por sua vez, é acompanhado pelo incremento do rendimento de polpa.

Para a variável rendimento de polpa, houve correção significativa $(p \leq 0,05)$ positiva com as características comprimento $\left(0,912^{*}\right)$ e diâmetro $\left(0,958^{*}\right)$ do fruto, e negativa com a porcentagem de casca $(-0,809 *)$ e de caroço ($0,998^{*}$ ) (Tabela 3). Indicando que, quanto maior o comprimento e o diâmetro, e menor a porcentagem de casca e caroço maior o rendimento de polpa. Portanto, os valores de comprimento e diâmetro são diretamente proporcionais, e os de porcentagem de casca e de caroço são inversamente proporcionais aos valores de rendimento de polpa. De acordo com Costa et al. (2015), correlações significativas entre o rendimento de polpa e os outros caracteres, como comprimento do fruto e largura do fruto, podem estar relacionados com correlações ambientais.

A firmeza da polpa teve correlação significativa $(p \leq 0,05)$ e negativa com o teor de sólidos solúveis $\left(-0,859^{*}\right)$, mostrando que quanto maior o teor de sólidos solúveis, menor a firmeza da polpa dos frutos de cajá-mangueira. Esta correlação também foi citada por Costa et al. (2015), em frutos de manga 'Ubá' (Mangifera indica L.), provenientes do município de Visconde do Rio Branco, MG, Brasil.

A perda de firmeza dos frutos ocorre em paralelo ao avanço do estádio de amadurecimento, em paralelo a elevação no teor de sólidos solúveis, visto que ocorre à hidrólise de polissacarídeos dentre eles o amido, resultando no aumento da concentração de açúcares solúveis (PINTO et al., 2013).

Para a variável $\mathrm{pH}$, constatou correlação significativa negativa $(p \leq 0,05)$ com a acidez titulável $\left(-0,764^{*}\right)$ (Tabela 3$)$, sinal de que o aumento do $\mathrm{pH}$ é inversamente proporcional ao aumento da acidez dos frutos. Nascimento et al. (2014), ao avaliarem a correlação entre as caracterização física e físico-química de frutos de mangabeira da região Oeste da Bahia, também descreveram correlação significativa negativa entre $\mathrm{pH} \times \mathrm{TA}$.

A relação SS/AT correlacionou negativamente, com a acidez titulavel $\left(-1,00^{*}\right)$, em nível de $5 \%$, portanto com a elevação da acidez ocorreu a redução da relação SS/AT ou vice-versa (Tabela 3), o que era esperado. Esta correlação também foi descrita por Silva et al. (2012), que ao avaliarem a diversidade genética, com base em características físicas e químicas, de frutos de diferentes cultivares de mangueiras (Hancornia speciosa). Estes autores também relatam que o ácido cítrico, assim como outros ácidos, reduz seu, contudo como o amadurecimento

Avaliar as correlações entre características físicas e físico-química de interesse é de grande importância, pois fornecem dados para programas de melhoramento, visto que as características correlacionadas significativamente aumentam a eficiência da seleção e classificação de genótipos superiores, para obtenção de ganhos genéticos (BORGES et al., 2011; SILVA et al., 2013). 
Tabela 3. Estimativa de coeficientes de correlação linear simples entre variáveis comprimento (L), diâmetro (D), peso de fruto (PF), rendimento de polpa (RP), porcentagem de casca (PB) e porcentagem de semente (PS), firmeza (F), potencial hidrogeniônico $(\mathrm{pH})$, acidez titulável (AT), sólido solúvel (SS) e relação Sólido solúvel/Acidez titulável (SS/AT).

\begin{tabular}{|c|c|c|c|c|c|c|c|c|c|c|c|}
\hline & C & D & PF & PC & PS & $\mathbf{R P}$ & $\mathbf{F}$ & $\mathrm{pH}$ & AT & SS & SS/AT \\
\hline C & 1,000 & & & & & & & & & & \\
\hline D & $0,992 *$ & 1,000 & & & & & & & & & \\
\hline PF & $0,863^{*}$ & $0,790^{*}$ & 1,000 & & & & & & & & \\
\hline PC & $0,357^{\mathrm{ns}}$ & $0,475^{\mathrm{ns}}$ & $-0,163^{\mathrm{ns}}$ & 1,000 & & & & & & & \\
\hline PS & 0,934 & $0,973^{\mathrm{ns}}$ & $0,626^{\mathrm{ns}}$ & $0,667^{\mathrm{ns}}$ & 1,000 & & & & & & \\
\hline $\mathbf{R P}$ & $0,912 *$ & $0,958^{*}$ & $0,880 *$ & $-0,809 *$ & $-0,998^{*}$ & 1,000 & & & & & \\
\hline $\mathbf{F}$ & $-0,955^{\mathrm{ns}}$ & $-0,909^{\text {ns }}$ & $-0,974^{\mathrm{ns}}$ & $-0,065^{\mathrm{ns}}$ & $-0,787^{\mathrm{ns}}$ & $0,750^{\mathrm{ns}}$ & 1,000 & & & & \\
\hline pH & $-0,000^{\mathrm{ns}}$ & $0,130^{\mathrm{ns}}$ & $-0,505^{\mathrm{ns}}$ & $0,934^{\mathrm{ns}}$ & $0,357^{\mathrm{ns}}$ & $-0,410^{\mathrm{ns}}$ & $0,296^{\mathrm{ns}}$ & 1,000 & & & \\
\hline AT & $-0,931^{\mathrm{ns}}$ & $-0,971^{\mathrm{ns}}$ & $-0,620^{\mathrm{ns}}$ & $-0,673^{\mathrm{ns}}$ & $-1,000^{\mathrm{ns}}$ & 0,999* & $0,782^{\mathrm{ns}}$ & $-0,764 *$ & 1,000 & & \\
\hline SS & $-0,779^{\text {ns }}$ & $-0,854^{\text {ns }}$ & $-0,357^{\text {ns }}$ & $-0,863^{n s}$ & $-0,952^{n s}$ & $0,968^{\mathrm{ns}}$ & $-0,859 *$ & $-0,626^{\mathrm{ns}}$ & $0,950^{\text {ns }}$ & 1,000 & \\
\hline SS/AT & $0,927^{\mathrm{ns}}$ & $0,968^{\mathrm{ns}}$ & $0,611^{\mathrm{ns}}$ & $0,681^{\mathrm{ns}}$ & $1,000^{\text {ns }}$ & $-0,799^{\text {ns }}$ & $-0,775^{\mathrm{ns}}$ & $0,374^{\text {ns }}$ & $-1,00^{*}$ & $-0,957^{\mathrm{ns}}$ & 1,000 \\
\hline
\end{tabular}

* Significativo ao nível de $5 \%$ de probabilidade $(p \leq 0,05),{ }^{\text {ns }}$ Não significativo.

\section{CONCLUSÕES}

As características físicas e físico-químicos dos frutos proveniente da microrregião do Litoral Norte indicam que estes podem ser destinados para o consumo de frutas frescas, como também para industrialização, por apresentarem rendimento de polpa, teor de SS AT, superior ao mínimo aceitável pelo padrão de identidade e qualidade (PIQ).

Os resultados da análise de variância demonstraram a existência de correlações lineares simples significativas entre as características físicas e químicas analisadas, indicando a existência de caracteres, como as dimensões dos frutos ou teor de sólidos solúveis para estimar parâmetros de produção, de seleção e qualidade dos frutos da cajá-mangueira.

\section{AGRADECIMENTOS}

Ao Conselho Nacional de Desenvolvimento Científico e Tecnológico (CNPq) pelo auxílio financeiro na execução do presente trabalho e pela concessão da bolsa de iniciação cientifica ao primeiro autor.

\section{REFERÊNCIAS}

AOAC. Official methods of analysis of the Association of Official Analytical Chemistry. 20. ed. Washington: AOAC, 2016.

AROUCHA, E.M.M.; SOUZA, C.S.M.; SOUZA, A.E.D.; FERREIRA, R.M.A. AROUCHA FILHO, J.C. Qualidade pós-colheita da cajarana em diferentes estádios de maturação durante armazenamento refrigerado. Revista Brasileira de Fruticultura, v.34, n.2, p.391-399, 2012. http://dx.doi.org/10.1590/S0100$\underline{29452012000200011}$

BARTOO, S.A.; BADRIE, N. Physicochemical, nutritional and sensory quality of stirred 'dwarf' golden apple (Spondias cytherea Sonn) yoghurts. International Journal of Food Sciences and Nutrition, v.56, n.6, p.445-454, 2005. http://dx.doi.org/10.1080/09637480500409905

BENEVIDES, S.D.; RAMOS, A.M.; STRINGHETA, P.C.; CASTRO, V.C. Qualidade da manga e polpa da manga Uba. Ciência e Tecnologia de Alimentos, v.28, n.3, p.571-578, 2008. http://dx.doi.org/10.1590/S0101$\underline{20612008000300011}$

BORGES, V.; SOBRINHO, F.S.; LÉDO, F.J.S.; KOPP, M.M. Associação entre caracteres e análise de trilha na seleção de progênies de meios irmãos de Brachiaria ruziziensis. Revista Ceres, v.58, n.6, p.65-772, 2011. http://dx.doi.org/10.1590/S0034$\underline{737 \times 2011000600013}$

BRASIL. Ministério da Agricultura, Pecuária e do Abastecimento. Instrução Normativa no 122, de 10 de setembro de 1999. Diário Oficial da República Federativa do Brasil, Brasília, 13 de setembro de 1999. Seção $1 .$. 
BRASIL. Normas Analíticas do Instituto Adolfo Lutz: métodos químicos e físicos para análise de alimentos. São Paulo: IAL, 2008.

CARVALHO, J.E.U.; NAZARÉ, R.F.R.; OLIVEIRA, W.M. Características físicas e físico-químicas de um tipo de bacuri (Platonia insignis Mart.) com rendimento industrial superior. Revista Brasileira de Fruticultura, v.25, n.2, p.326-328, 2003. http://dx.doi.org/10.1590/S0100$\underline{29452003000200036}$

CARVALHO, P.C.L.; RITZINGER, R.; SOARES FILHO, W.S.; LEDO, C.A.S. Características morfológicas, físicas e químicas de frutos de populações de umbu cajazeira no Estado da Bahia. Revista Brasileira de Fruticultura, v.30, n.1, p.140-147, $2008 . \quad$ http://dx.doi.org/10.1590/S0100$\underline{29452008000100026}$

CHITARRA, M. I. F.; CHITARRA, A. B. Pós-colheita de frutas e hortaliças: fisiologia e manuseio. 2.ed. Lavras: UFLA, 2005. 523p.

COSTA, F.R.; NEDER, D.G.; REGO E.R.; REGO, M.M.; NEDER, D.G.; SILVA, S.M.; SCHUNEMANN, A.P.P. Análise biométrica de frutos de umbuzeiro do semiárido brasileiro. Bioscience Journal, v.31, n.3, p.682-690, 2015. http://dx.doi.org/10.14393/BJ-v31n3a2015-22844

DAMIANI, C.; SILVA, F.A.; AMORIM, C.C.M.; SILVA, S.T.P.; BASTOS, I.M.; ASQUIERI, E.R.; VERA, R. Néctar misto de cajá-manga com hortelã: caracterização química, microbiológica e sensorial. Revista Brasileira de Produtos Agroindustriais, v.13, n.3, p.299-307, 2011. http://dx.doi.org/10.15871/1517-

8595/rbpa.v13n3p301-309

DANTAS, A.L.; SILVA, S.M., DANTAS, R.L.; SOUSA, A.S.B.; SCHUNEMANN, A.P.P. Desenvolvimento, fisiologia da maturação e indicadores do ponto de colheita de frutos da umbugueleira (Spondias sp.). Revista Brasileira de Fruticultura, v.38, n.1, p.033-042, 2016. http://dx.doi.org/10.1590/01002945-271/14

DAULMERIE, S. Investigations on golden apple (Spondias cytherea) production with particular reference to postharvest technology and processing. Trinidad and Tobago: Inter-American Inst. for Cooperation on Agriculture, 1994. 53p.
FAGUNDES, G.R.; YAMANISHI, O.K. Características físicas e químicas de frutos de mamoeiro do grupo Solo comercializados em 4 estabelecimentos de Brasília - DF. Revista Brasileira de Fruticultura, Jaboticabal, v.23, n.3, p.541-545, 2001. http://dx.doi.org/10.1590/S0100$\underline{29452001000300018}$

FERREIRA, D.F. SISVAR: A Guide for its Bootstrap procedures in multiple comparisons. Ciência \& Agrotecnologia, v.38, n.2, p.109-112, 2014. http://dx.doi.org/10.1590/S1413$\underline{70542014000200001}$

FORTALEZA, J.M.; PEIXOTO, J.R.; JUNQUEIRA, N.T.V.; OLIVEIRA, A.T.; RANGEL, L.E.P. Características físicas e químicas em nove genótipos de maracujá azedo cultivado sob três níveis de adubação potássica. Revista Brasileira de Fruticultura, v.27, n.1, p.124-127, 2005. http://dx.doi.org/10.1590/S0100$\underline{29452005000100033}$

FRANQUIN, S.; MARCELIN, O.; REYNES, M.; BRILLOUET, J.M. Characterization of starch and cell walls from mature-green ambarella (Spondias cytherea Sonnerat) and their enzymatic hydrolysis. European Food Research and Technology, v.226, n.4, p.905-913, 2008. https://doi.org/10.1007/s00217-007-0613-0

GANGA, R.M.D.; CHAVES, L.C.; NAVES, R.V., NASCIMENTO, J.L. Caracterização de frutos e árvores de populações naturais de Hancornia speciosa Gomes do cerrado. Revista Brasileira de Fruticultura, Jaboticabal, v.32, n.1, p.101-113, 2010. http://dx.doi.org/10.1590/S010029452010005000019

GOMES, R. P. Fruticultura brasileira. 13. ed. São Paulo: Nobel, 2007. 446p.

GONDIM, P.J.S.; SILVA, S.M.; PEREIRA, W.E.; DANTAS, A.L.; CHAVES NETO, J.R.; SANTOS, L.F. Qualidade de frutos de acessos de umbu-cajazeira (Spondias sp.). Revista Brasileira de Engenharia Agrícola e Ambiental, v.17, n.11, p.1217-1221, $2013 . \quad$ https://doi.org/10.1590/S1415$\underline{43662013001100013}$

GUERRA, N.B.; LIVERA, A.V. Correlação entre o perfil sensorial e determinações físicas e químicas do abacaxi cv. 'Pérola'. Revista Brasileira de Fruticultura, v.21, n.1, p. 32-35, 1999. 
INSTITUTO ADOLFO LUTZ. Normas analíticas, métodos químicos e físicos para análise de alimentos. 2. ed. São Paulo: IAL, 2005.

ISHAK, S.A.; ISMAIL, N.; NOOR, M.A.M.; AHMAD, $H$. Some physical and chemical properties of ambarella (Spondias cytherea Sonn.) at three different stages of maturity. Journal of Food Composition and Analysis, v.18, n.8, p.819-827, 2005.

http://dx.doi.org/10.1016/j.jfca.2004.11.007

JACOMINO, A.P.; BRON, L.U.; KLUGE, R.A. Avanços em tecnologia pós-colheita de mamão. In: MARTINS, D.S. (Ed.). Papaya Brasil: qualidade do mamão para o mercado interno. Vitória: Incaper, 2003. p.283-293.

JANICK, J.; PAULL, R. E. The encyclopedia of fruit \& nuts. Wallingford: $C A B I$ International Publishing, 2008.

954p.

https://doi.org/10.1079/9780851996387.0000

KÖPPEN, W. Climatologia. México: Fundo de Cultura Económica, 1948. 71p.

LAGO-VANZELA, E.S.; RAMIN, P.; UMSZA-GUEZ, M.A.; SANTOS, G.V.; GOMES, E; SILVA, R. Chemical and sensory characteristics of pulp and peel 'cajámanga' (Spondias cytherea Sonn.) jelly. Ciência e Tecnologia de Alimentos, v.31, n.2, p.398-405, $2011 . \quad$ http://dx.doi.org/10.1590/S010120612011000200018

LIMA, E.D.P.A.; LIMA, C.A.A.; ALDRIGUE, M.L.; GONDIM, P.J.S. Caracterização física e química dos frutos da umbu-cajazeira (Spondias spp.) em cinco estádios de maturação, da polpa congelada e néctar. Revista Brasileira de Fruticultura, v.24, n.2, p.338-343, 2002. http://dx.doi.org/10.1590/S0100-

29452002000200013

LIRA JÚNIOR, J.S.; BEZERRA, J.E.F.; MOURA, R.J.M.; SANTOS, V.F. Repetibilidade da produção, número e peso de fruto em cirigueleira (Spondias purpurea L.). Revista Brasileira de Fruticultura, v.36, n.1, p.214-220, 2014. http://dx.doi.org/10.1590/0100-2945-294/13

LIRA JÚNIOR, J.S.; MUSSER, R.S.; MELO, E.A.; MACIEL, M.I.S.; LEDERMAN, I.E.; SANTOS, V.F. Caracterização física e físico-química de frutos de cajá-umbu (Spondias spp.). Ciência e Tecnologia de Alimentos, v.25, n.4, p.757-761, 2005. https://doi.org/10.1590/s0101$\underline{20612005000400021}$

LORENZI, H., BACHER, L., LACERDA, M., SARTORI, $S$. Frutas brasileiras e exóticas cultivadas: de consumo in natura. 1.ed. São Paulo: Instituto Plantarum de Estudos da Flora, 2006. 672p.

MENEZES, P.H.S.; SOUZA, A.A.; SILVA, E.S.; MEDEIROS, R.D.; BARBOSA, N.C.; SORIA, D.G. Influência do estádio de maturação na qualidade físico-química de frutos de umbu (Spondias tuberosa). Scientia Agropecuaria, v.8, n.1, p.7378 , 2017. http://dx.doi.org/10.17268/sci.agropecu.2017.01. $\underline{07}$

NASCIMENTO, R.S.M.; CARDOSO, J.A.; COCOZZA, F.D.M. Caracterização física e físico-química de frutos de mangabeira (Hancornia speciosa Gomes) no oeste da Bahia. Revista Brasileira de Engenharia Agrícola e Ambiental, v.18, n.8, p.856-860, 2014. http://dx.doi.org/10.1590/18071929/agriambi.v18n08p856-860

PALIYATH, G.; MURR, D. P. Biochemistry of Fruits. In: PALIYATH, G.; MURR, D. P.; HANDA, A. K.; LURIE, S. Postharvest biology and technology of fruits, vegetables and flowers. Blackwell Publishing, 2008. p. 19-50.

PAULL, R.E.; GROSS, K.; QIU, Y. Changes in papaya cell walls during fruit ripening. Postharvest Biology and Technology, v.16, n.1, p.79-89, 1999. https://doi.org/10.1016/S0925-5214(98)00100-8

PINTO, P.M.; JACOMINO, A.P.; SILVA, S.R.; ANDRADE, C.A.W. Ponto de colheita e maturação de frutos de camu-camu colhidos em diferentes estádios. Pesquisa Agropecuária Brasileira, v.48, n.6, p.605-612, 2013. http://dx.doi.org/10.1590/S0100$\underline{204 \times 2013000600005}$

SANTOS, M.B.; CARDOSO, R.L.; FONSECA, A.A.O.; CONCEIÇÃO, M.N. Caracterização e qualidade de frutos de umbu-cajá (Spondias tuberosa $\mathrm{x} \mathrm{S}$. mombin) provenientes Do Recôncavo sul da Bahia. Revista Brasileira de Fruticultura, v.32, n.4, p.1089-1097, 2010.

http://dx.doi.org/10.1590/s0100$\underline{29452011005000015}$ 
SILVA, D.F.P.; SILVA, J.O.C.; MATIAS, R.G.P.; RIBEIRO, M.R.; BRUCKNER, C.H. Correlação entre características quantitativas e qualitativas de frutos de pessegueiros na geração $F 2$ cultivados em região subtropical. Revista Ceres, v.60, n.1, p.53-58, 2013. http://dx.doi.org/10.1590/S0034737X2013000100008

SILVA, D.F.P.; SIQUEIRA, D.L.; ROCHA, A.; SALOMÃO, L.C.C.; MATIAS, R.G.P.; STRUIVING, T.B. Diversidade genética entre cultivares de mangueiras, baseada em caracteres de qualidade dos frutos. Revista Ceres, v.59, n.2, p.225-232, $2012 . \quad$ http://dx.doi.org/10.1590/s0034737X2012000200011

SILVA, G.G.; MORAIS, P.L.D.; ROCHA, R.H.C.; SANTOS, E.C.; SARMENTO, J.D.A. Caracterização do fruto de cajaranazeira em diferentes estádios de maturação. Revista Brasileira de Produtos Agroindustriais, v.1, n.2, p.159-163, 2009. http://dx.doi.org/10.15871/1517-

8595/rbpa.v11n2p159-163

VIANA, E.S.; REIS, R.C.; SENA, L.O.; SANTOS JÚNIOR, M.B.; SILVA, P.N.R. Produção de bananaspassa com frutos de variedades melhoradas e avaliação da qualidade físico-química e sensorial. Boletim Centro de Pesquisa de Processamento de Alimentos, v.35, n.1, p.1-10, 2017. http://dx.doi.org/10.5380/cep.v35i1.55944 